\title{
Stucco panels of Room VI in the Galleria Borghese (Rome): Physical-chemical analysis and microclimate characterization
}

\author{
Alessia Caratelli ${ }^{a}$, Anna Maria Siani ${ }^{a}, b, *$, Giuseppe Rocco Casale ${ }^{a}$, Alessandro Paravicini ${ }^{c}$, \\ Kristina Hermann Fiore ${ }^{\mathrm{d}}$, Dario Camuffo ${ }^{\mathrm{e}}$ \\ a Sapienza Università di Roma, Physics Department, p.le A. Moro 2, 00185 Rome, Italy \\ b Centro di Ricerca de "La Sapienza" sulle Tecnologie per l'Ambiente, p.le A. Moro 2, 00185 Rome, Italy \\ ${ }^{\mathrm{c}}$ Tecno-el S.r.l., via degli Olmetti 38, Formello, Rome, Italy \\ d Borghese Gallery, P.le del Museo Borghese, 5, 00197 Rome, Italy \\ e National Research Council, Institute of Atmospheric Sciences and Climate, Corso Stati Uniti 4, 35127 Padova, Italy
}

\section{A R T I C L E I N F O}

\section{Article history:}

Received 30 November 2012

Received in revised form 31 January 2013

Accepted 11 February 2013

\section{Keywords:}

Indoor microclimate

Artificial lighting

Material analysis

Deterioration

\begin{abstract}
A B S T R A C T
A multidisciplinary approach was used to study the reason behind the deterioration of four stucco panels that decorate the vault of Room VI in the Galleria Borghese in Rome. During the last nine years the panels were subjected twice to restoration because some cracks, which appeared over the surface of the reliefs jeopardizing the integrity of the gladiators.

Since the deterioration continued diagnostic investigations of the components of the stucco panels were performed to analyze both the elements and compounds, and the mineralogical structure. A microclimate study was conducted to assess the impact of the indoor environment on the panels. Measurements and statistical analysis of the data were performed in accordance with the European Standards EN 15757:2010, EN 15758:2010, and EN 16242:2012.

It was concluded that the deterioration is related to high temperatures in a dry environment exacerbated by artificial lighting with incandescent lamps, located in the proximity of the panels and continuously on for $12 \mathrm{~h}$ daily. The body heat released by numerous visitors on a daily basis is an additional problem which should not be overlooked.
\end{abstract}

(c) 2013 Elsevier B.V. All rights reserved.

\section{Introduction}

In 1606, Scipione Borghese, a keen art collector, built the today so called Galleria Borghese in Rome to store and exhibit his valuable art collection [1]. The Gallery consists of an underground service floor, a ground floor where sculptures and paintings are displayed, and a first floor exhibiting only paintings. The Galleria Borghese underwent an extensive, 14-year long restoration and was re-opened to the public in 1997.

This paper is concerned with Room VI, in the north-western side of the ground floor, and in particular with four stucco panels (Fig. 1) located on the lower part of the vault, $6 \mathrm{~m}$ above floor level. The panels are copies of Roman originals kept in the Vatican Museum. These were originally copied and drafted by Vincenzo Pacetti (1758-1826) and later realized by the sculptor Costantino

\footnotetext{
* Corresponding author at: Sapienza Università di Roma, Physics Department, p.le A. Moro 2, 00185 Rome, Italy. Tel.: +39 0649913479 ; fax: +39 064463158.

E-mail address: annamaria.siani@uniroma1.it (A.M. Siani).
}

Mazzoni (active in the second half of the 18th century). Each basrelief panel represent six gladiators with one leg protruding from hip to heel (Fig. 2). Some cracks occurred over the relief threatening the detachment of the legs. During the last nine years the panels were restored twice, in 2001 and in 2009 [Fiore personal communication, 2009].

Room VI (covering about $100 \mathrm{~m}^{2}$ ) is never exposed to direct sunlight. It has two doors and four shaded windows that are open only for cleaning, around $7.00 \mathrm{am}$, and is illuminated with artificial lighting. The Museum's opening hours are from $9.00 \mathrm{am}$ to $7.00 \mathrm{pm}$. Five visits are scheduled per day, up to 360 people maximum simultaneously allowed in the Gallery. The total number of visitors is rather large, e.g. 486,000 in 2008 [2].

This paper identifies and discusses the causes of the deterioration of the stucco panels through a chemical-physical analysis of the material made in situ and in laboratory, and the characterization of the microclimate and the artificial lighting, to determine their impact on Room VI, and on the panels. The final objective of the study is to suggest measures to return to the historic climate with a better choice of lighting and a better Room management. 


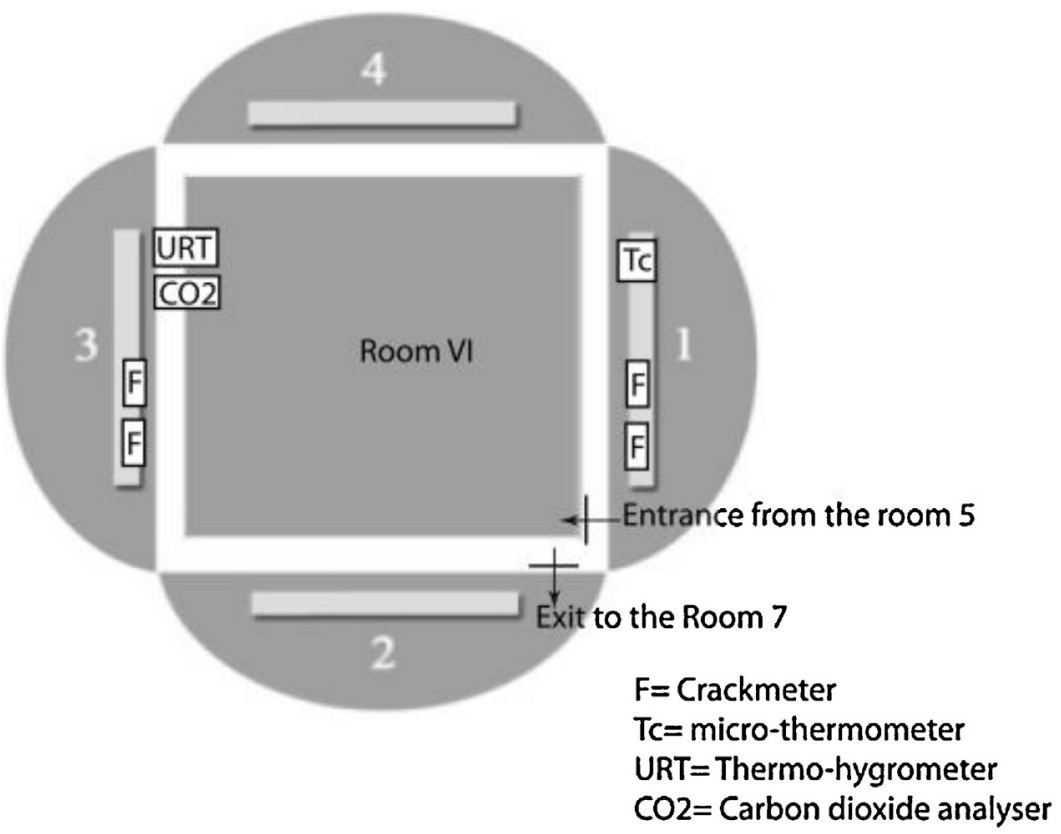

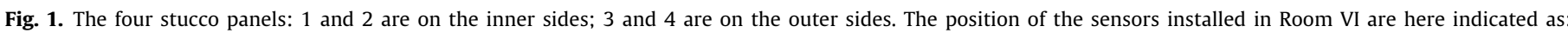
$F=$ crack-meters; $\mathrm{Tc}=$ micro-thermometer; $\mathrm{URT}=$ thermo-hygrometer; and $\mathrm{CO}_{2}=$ carbon dioxide analyser.

\section{Methods}

\subsection{The stucco panels and investigation methodologies}

The panels were executed using a special plaster technique called "scagliola" [3], based on a mixture of calcium sulphate dehydrate $\left(\mathrm{CaSO}_{4} \cdot 2 \mathrm{H}_{2} \mathrm{O}\right)$, lime $\left(\mathrm{Ca}(\mathrm{OH})_{2}\right)$, an organic glue and sand [3-5]. During the 2001 restoration the panels were cleaned and consolidated to prevent the detachment of some of the legs. This intervention allowed to recognized that the protruding parts of the panels were highly vulnerable since they have no supporting internal structure. In 2008, a team of the Central Institute for Restoration (ICR) in Rome performed a stratigraphic analysis on a thin section of the panel identifying four finish layers. A white deep layer made of a mixture of gypsum and casein; an underlying layer; a yellow paint layer and a varnish layer. Air bubbles resulted from inadequate kneading of the stucco created cavities in the material that weakened parts of the relief and as a result a leg broke off. No further analyses were performed to verify more accurately the composition and homogeneity of the mixture.

In March 2009 a leg had fallen on the ledge, in front of the panel no. 3 (Fig. 1), and a second restoration was necessary to restore and consolidate the detached part with hydraulic lime mortar and the surface with bandages fixed with acrylic resin. In the context of this restoration, directed by K. Hermann Fiore, a microclimate control was included. To ascertain the use of the scagliola technique

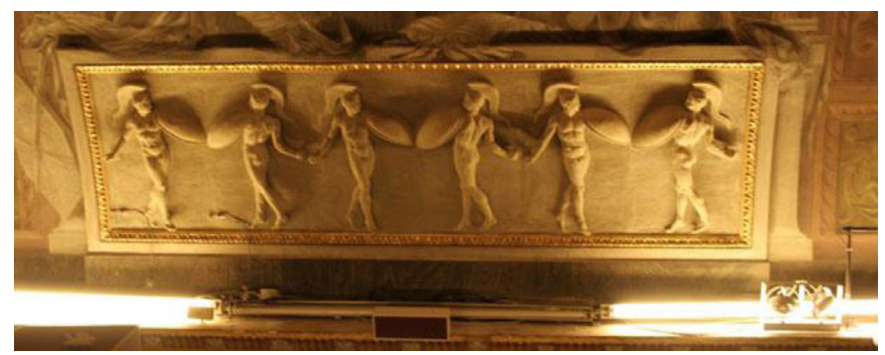

Fig. 2. Stucco panels in "bas relief" representing the six gladiators in the act of making an ancient Greek dance of war. some diagnostic detailed analysis were performed to find out both the elements and the compounds of the material, and its mineralogical structure, with the following diagnostic techniques: X-ray fluorescence (XRF); X-ray diffraction (XRD); Scanning Electron Microscope with Energy Dispersive X-ray Spectroscopy (SEM/EDS); Optic Stereoscopic Microscope (OSM) in reflected and transmitted light; Optic Petrographic Microscope (OPM) in reflected light; and nuclear magnetic resonance (NMR).

A specimen of $1 \mathrm{~cm}$ diameter was sampled from the inside of the leg and analyzed with OSM, OPM and in addition with SEM/EDS, to find out the composition of the material. The analysis was also performed on panel no. 3 with XRF technique. The chemical components were analyzed on additional samples with XRD: a specimen was sampled from the bottom of panel no. 3 ("fondo stucco"); two from panel no. 1 (from the bottom and from the surface of a leg). The same specimen was analyzed with nuclear magnetic resonance (NMR). First it was treated with chloroform to extract the lipid compounds, and second with deuterium oxide $\left(\mathrm{D}_{2} \mathrm{O}\right)$ to extract the protein content.

\subsection{Measuring the indoor climate and the panel response}

In the last decade a growing number of studies on environmental conditions of museums and buildings housing artifacts have shown that a stable microclimate is beneficial for their conservation [6-10]. The application of numerical simulation models of heat, air and moisture (HAM) circulation in buildings has become a common practice to control the performance of indoor climate [11]. The thermal interaction between outdoor climate and wall materials and their influence on indoor temperatures was studied in $[12,13]$.

Artifacts, depending on their material and age, react to trends and fluctuations in temperature, humidity and lighting. This form of adaptation may be harmful for the internal stresses of artifacts or for other potential causes of damage [14].

The microclimate of Room VI required monitoring the most important environmental parameters $[10,14]$ in accordance with the European Standards [15-18].

The microclimate monitoring was carried out from April 1st 2009 to October 20th 2009 (technical and financial reasons limited 
the monitoring to this period only). The period was chosen because it is the warmest of the year, the most crucial period for the stucco panel because of the overheating and the generation of internal stress.

The measurement system, consisting of 1 temperature and humidity electronic recorder, 1 surface thermometer, 1 carbon dioxide analyser and 4 crack-meters to control the time span of width changes in some cracks, was installed on panels no. 1 and no. 3 , as shown in Fig. 1. Air temperature (Ta) was measured with a platinum resistance sensor (accuracy: $0.3^{\circ} \mathrm{C}$, range of measure: $-40^{\circ} \mathrm{C}$ to $+60{ }^{\circ} \mathrm{C}$, repeatability: $0.1{ }^{\circ} \mathrm{C}$ ); relative humidity ( $\left.\mathrm{RH}\right)$ was measured with a capacitive hygrometer (accuracy: $1.5 \%$ in the $10-95 \%$ RH interval, repeatability: better than $0.5 \%$ ). The surface temperature of the panel (Tc) was measured with thermistors (accuracy: $0.1{ }^{\circ} \mathrm{C}$; range of measure: $-30^{\circ} \mathrm{C}$ to $+150{ }^{\circ} \mathrm{C}$, response time: $<1 \mathrm{~s}$ ).

The infrared (IR) instrument for measuring $\mathrm{CO}_{2}$ concentration (accuracy: $29 \mathrm{ppm}$, range of measure: from 0 to $2000 \mathrm{ppm}$ ) is an infrared gas analyzer based on the measure of the absorbed IR radiation by the air diffused into the instrument and compared it to the reference absorption radiation, without the gas.

The crack-meter (range of measure: 0-10 mm; accuracy: $0.25 \%$ of reading value) provides the measurement of the movement across the surface of the crack. It consisted of a conductive plastic potentiometer connected to a capacitor. According to the Ohm law the detected signal is proportional to the increase in length of the conductive element.

All sensors were connected to the GRILLO MMTS data logger with remote transmission of data. The unit used the GSM/GPRS (Global System for Mobile Communications/General Packet Radio System) technology for the data transmission to the server allowing the visualization of the data set and their download. For this study the following configuration was chosen: the acquisition time was set to $10 \mathrm{~min}$; the processing time was set to 60 min providing the minimum, maximum and the average of the recorded parameters.

In addition, to characterize the historic microclimate, air temperature and relative humidity collected in 2007 were analyzed and taking into account as reference year. The instruments had the same technical features and setup of those used in the 2009 campaign although they were installed $3 \mathrm{~m}$ above ground while in 2009 they rested at $6 \mathrm{~m}$.

\subsection{Measuring light}

Since the analysis of the material revealed the use of organic glue in the mixture (see below), light (mainly the shortwave UV) may alter the crystalline structure undergoing a polymerization process [6].

To ascertain the influence of the lighting on the degradation of the stucco panels, the intensity of lighting on the unit area, $E$ (expressed in lumen per square meters, i.e. $\mathrm{lx}$ ) and UVA (in $\mu \mathrm{W} \mathrm{lm}^{-1}$ ) measurements were performed in situ on panel no. 3, on March 8th, 2010, using a photo-radiometer (HD2302.0 by Delta OHM) with two probes: the LP 471 PHOT probe, for lighting analysis, with an accuracy of $0.5 \%$ on reading value and a range of detection from $0.01 \mathrm{~lx}$ to $200 \cdot 10^{3} \mathrm{~lx}$; the LP 471 UVA probe for UVA component analysis, with accuracy of 1 digit and a range of detection from $0.1 \cdot 10^{-3} \mathrm{~W} / \mathrm{m}^{2}$ and $2000 \mathrm{~W} / \mathrm{m}^{2}$.

Finally, to evaluate whether the lighting duration is adequate for the conservation of the material, the total annual dose of lighting (LO) was estimated grouping the measured $E$ values into four classes [23] ( $E \leq 50 \mathrm{~lx}$; 50-150 lx; 150-300 lx; $\geq 300 \mathrm{~lx}$ ) and considering the length of time lights are turned on during the day, and by summing up hourly values. Measurements were carried out on several areas of the protruding legs of panel no. 3 and on the background of the panel. Radiometric temperatures $\left(T_{\text {rad }}\right)$ were also

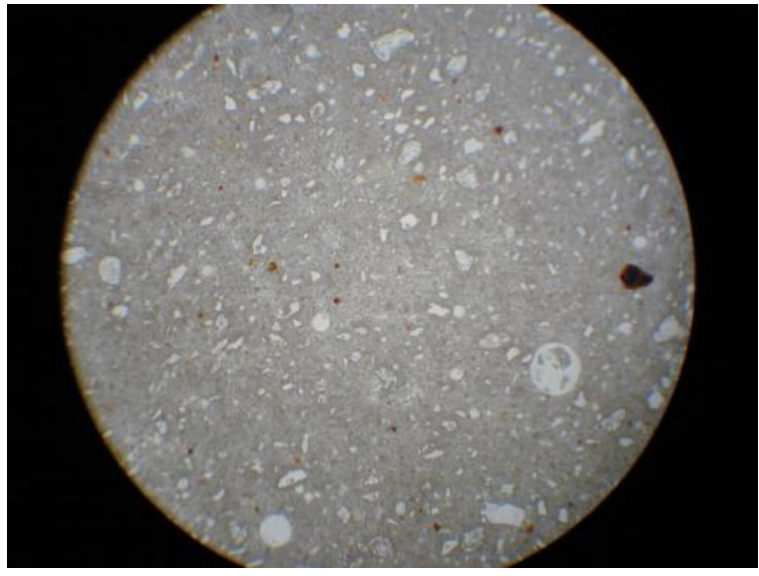

Fig. 3. Thin section observed at the stereo-microscope (OSM) with an enlargement of $15 \times$.

measured on the same areas using an infrared radiometer [PT-3LF by OPTEC].

\section{Experimental data and results}

\subsection{Material analysis}

The analysis with OSM both in reflected and transmitted light (with $7 \times$ and $15 \times$ magnification) showed a friable and porous groundmass (Fig. 3) with large and circular pores, with quartz, carbonate and aluminosilicate particles. The pores could be due to the organic compound alteration over time which produced the evaporation of $\mathrm{CO}_{2}$. The investigation carried out with the OPM microscope in reflected light (with an enlargement of $100 \times$ ), showed the characteristic reddish-brown color of the pozzolan component (Fig. 4).

The specimen taken from the inside of the leg was also analyzed using NMR technique to characterize the organic compound. The specimen was subjected to two types of extraction. The water extraction did not reveal lipid substances while the deuterium oxide $\left(\mathrm{D}_{2} \mathrm{O}\right)$ extraction showed a heavy molecular compound which could be a protein.

These results were reinforced by the common use of organic glue in the scagliola mixture as reported by [5].

The image performed using SEM/EDS with backscattered electrons showed more clearly the porous groundmass with lamellar crystals habit of gypsum and the carbonate and aluminosilicates

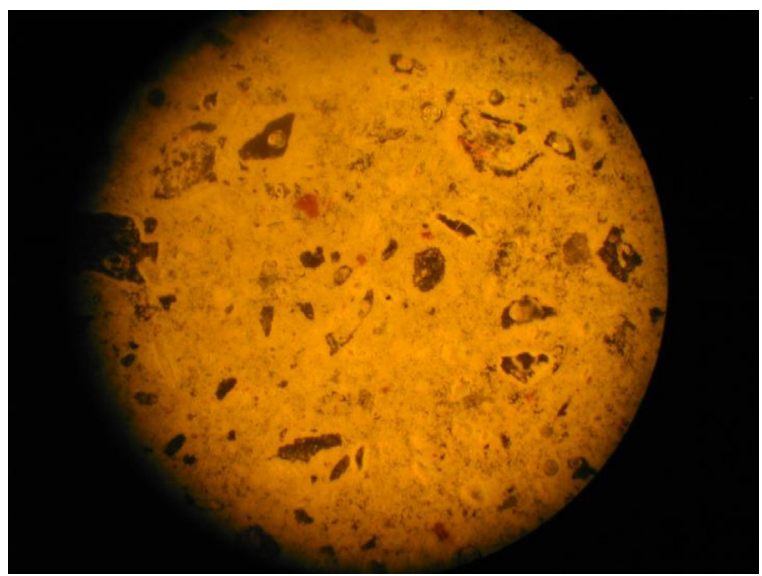

Fig. 4. Thin section observed at the petrographic microscope (OPM) with an enlargement of $100 x$. 


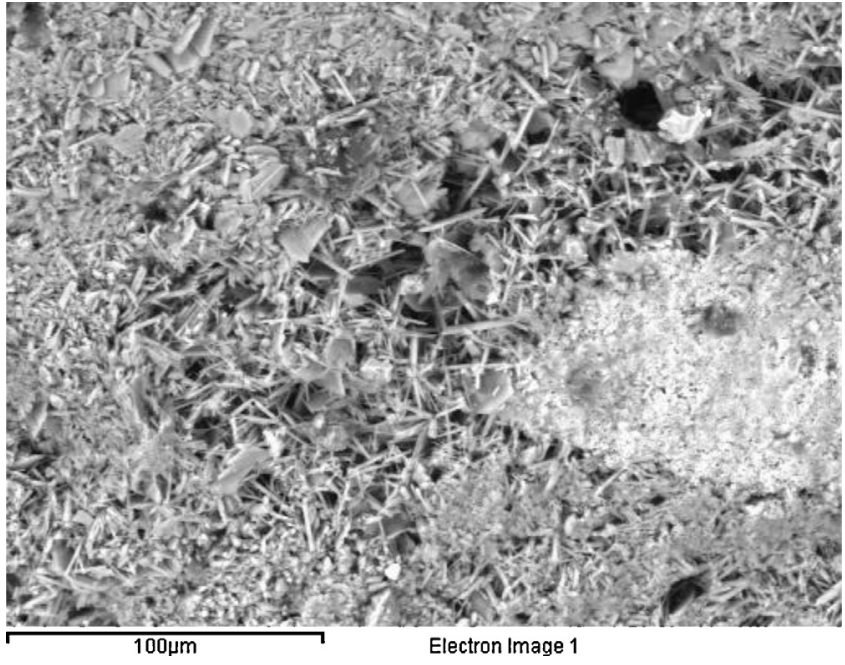

Fig. 5. SEM image with backscattered electrons.

aggregates (Fig. 5). The SEM/EDS analysis revealed the presence of calcium (Ca) and sulfur (S) in the groundmass, and of aluminum $(\mathrm{Al})$, silicon $(\mathrm{Si})$, calcium $(\mathrm{Ca})$, magnesium $(\mathrm{Mg})$ and iron $(\mathrm{Fe})$ in the particles composition. These results were also confirmed by the $\mathrm{XRF}$ analysis. They were also consistent with those results provided by the microscopy investigation on pozzolan, which is an aluminosiliceous material and can contain iron, sodium, potassium or magnesium oxides.

The XRD analysis was performed on some samples: from the inside part of the leg, from the bottom of panels no. 1 and no. 3 , and from the surface of the leg in panel no. 3. These investigations revealed the presence of the anhydrous calcium sulphate (anhydrite: $\left.\mathrm{CaSO}_{4}\right)$, magnesian calcite $\left(\mathrm{MgCO}_{3}\right)$ and quartz $\left(\mathrm{SiO}_{2}\right)$. The presence of both gypsum and anhydrite reinforced the hypothesis of a dangerous drying process that could have contributed over time to the cracks in the material.

\subsection{Microclimate measurements}

The European Standard EN 15757:2010 [15], which substituted the previous Italian Standard UNI 10969:2002 [19], both related to the risk of climate-induced mechanical damage in organic hygroscopic materials, establish the priority of the historic climate. If an object has been satisfactorily preserved for many years under the same climatic conditions, then it may be risky to change these conditions. This applies to wood but it also holds for other hygroscopic materials that suffer from shrinkage and swelling. Climate variability brings about dimensional changes with internal strain and stresses to which the object has adapted or resisted may be through the formation of internal cracks as expansion tends to follow the daily or seasonal cycles. The average of air temperature and relative humidity in the Room (at $6 \mathrm{~m}$ level) was computed over the period of the field campaign in 2009. The mean of air temperatures is $29.1^{\circ} \mathrm{C}$ and of $\mathrm{RH}$ readings is $41 \%$. A huge variety of stucco plaster exists and in the literature the most frequent recommendation is to keep plaster at temperature and $\mathrm{RH}$ as constant as possible. However no preferred temperature and $\mathrm{RH}$ ranges are indicated. A paper was found with the suggested ranges of temperature $\left(13-18^{\circ} \mathrm{C}\right)$ and from $35 \%$ to $45 \%$ for $\mathrm{RH}$ [20]. Our panel shows on average higher temperature while the $\mathrm{RH}$ falls within this range.

The decay observed in the panels in the last decade may be associated to the response of the stucco to daily or seasonal changes of thermo-hygrometric conditions in Room VI. To explore the longterm behavior of thermo-hygrometric conditions, we applied the European Standard [15] by calculating the central moving average
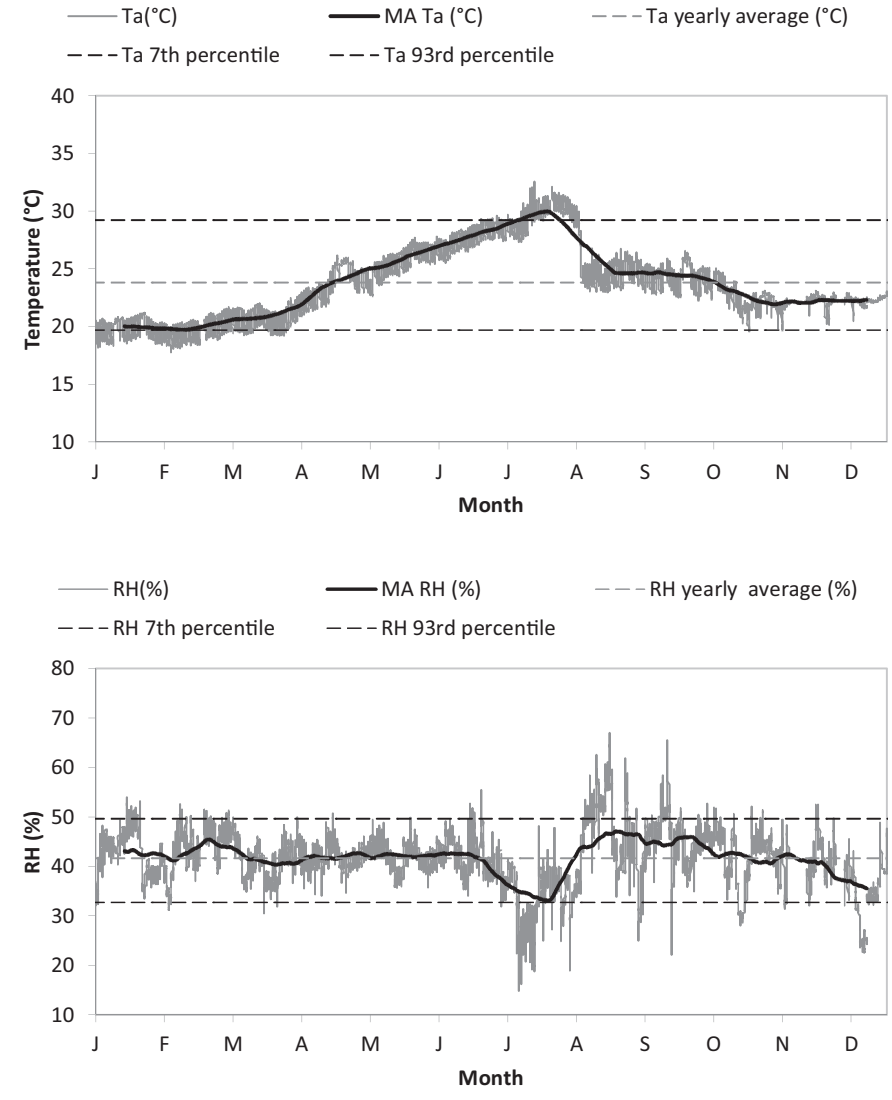

Fig. 6. Temporal behavior of Ta (upper panel) and RH (lower panel) with their central moving average (MA). The parameters were measured during 2007.

(MA) taken in a 30-day period on 2007 data. This sampling period filters the short-term fluctuations. Fig. 6 shows the temporal behavior of Ta and RH values during 2007, with their MAs. The seasonal expected air temperature increase during the summer (upper panel) ought to be noticed.

The temperature drop in August can be explained by the use of the air conditioning system in operation until the end of September. The RH pattern during summer is inversely correlated with Ta (lower panel). The yearly temperature average is $23.8^{\circ} \mathrm{C}$ ranging from $19.7^{\circ} \mathrm{C}$ (7th percentile) and $29.2^{\circ} \mathrm{C}$ (93rd percentile) The yearly RH average is $42 \%$ with the lower limit of $33 \%$ ( 7 th percentile) and the upper limit of 50\% (93rd percentile). These results further confirm that the temperature is too warm for the conservation of the stucco.

Thus the difference between their maximum and minimum (daily span), which allows studying the variability of the parameters and the sustainability of the material with regard to the environment, was determined. We assume as first approximation that the microclimatic cycle of the Room can be similar to those found for the Basilica of Santa Maria Maggiore, in Rome [21]. This assumption can be justified by the fact that both are old buildings with thick walls, which reduce the effect of external temperature and humidity variations. Moreover both buildings are affected by the same urban climate.

The range of temperature and $\mathrm{RH}$ assumed as representative of the historic cycle is $0-2.5^{\circ} \mathrm{C}$ and $0-10 \%$ respectively. These ranges were also compared with the ranges determined as the 7 th and 93rd percentiles of the short-term fluctuations [15] of the reference year. It was found that the new range $\left(0-2.6^{\circ} \mathrm{C}\right.$ for temperature and $0-14 \%$ for $\mathrm{RH}$ ) is consistent with the assumed range.

Looking at the Ta and RH daily span values (Fig. 7) it can be noticed that the thermo-hygrometric values in 2009 are often 


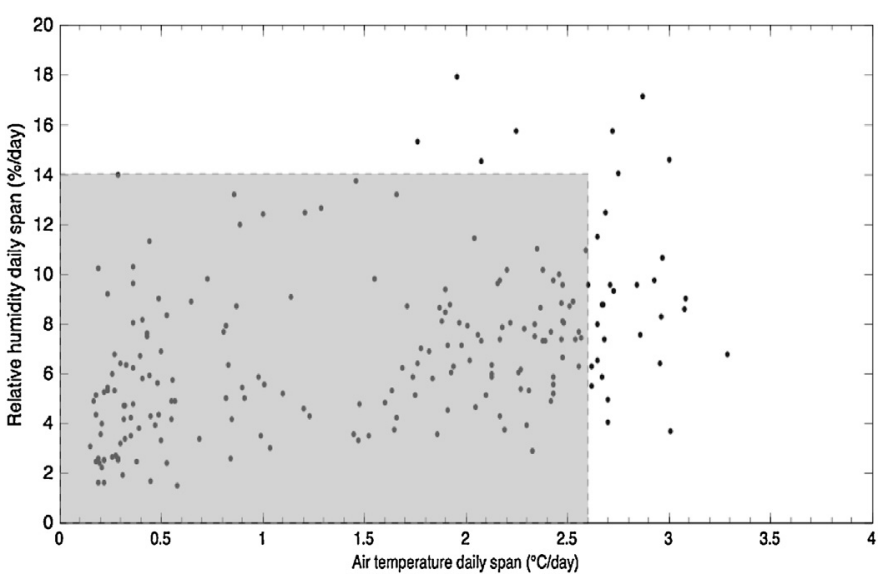

Fig. 7. The air temperature and relative humidity daily spans in 2009 . The gray rectangle shows the range of air temperature and relative humidity assumed as representative of the historic cycle.

within the "safe" area of $0-2.6^{\circ} \mathrm{C}$ for the temperature and $0-14 \%$ for relative humidity. The events with larger variations occurred mainly in June.

The frequency distribution (F\%) was then calculated for the environmental parameters. The frequency distribution of air temperatures at $4 \mathrm{~h}$ interval (Fig. 8, upper panel) showed that the reached maxima were $26^{\circ} \mathrm{C}$ in spring and $31^{\circ} \mathrm{C}$ in summer, the first maximum occurred in the afternoon (12:00-16:00) while the second in the evening (17:00-20:00).
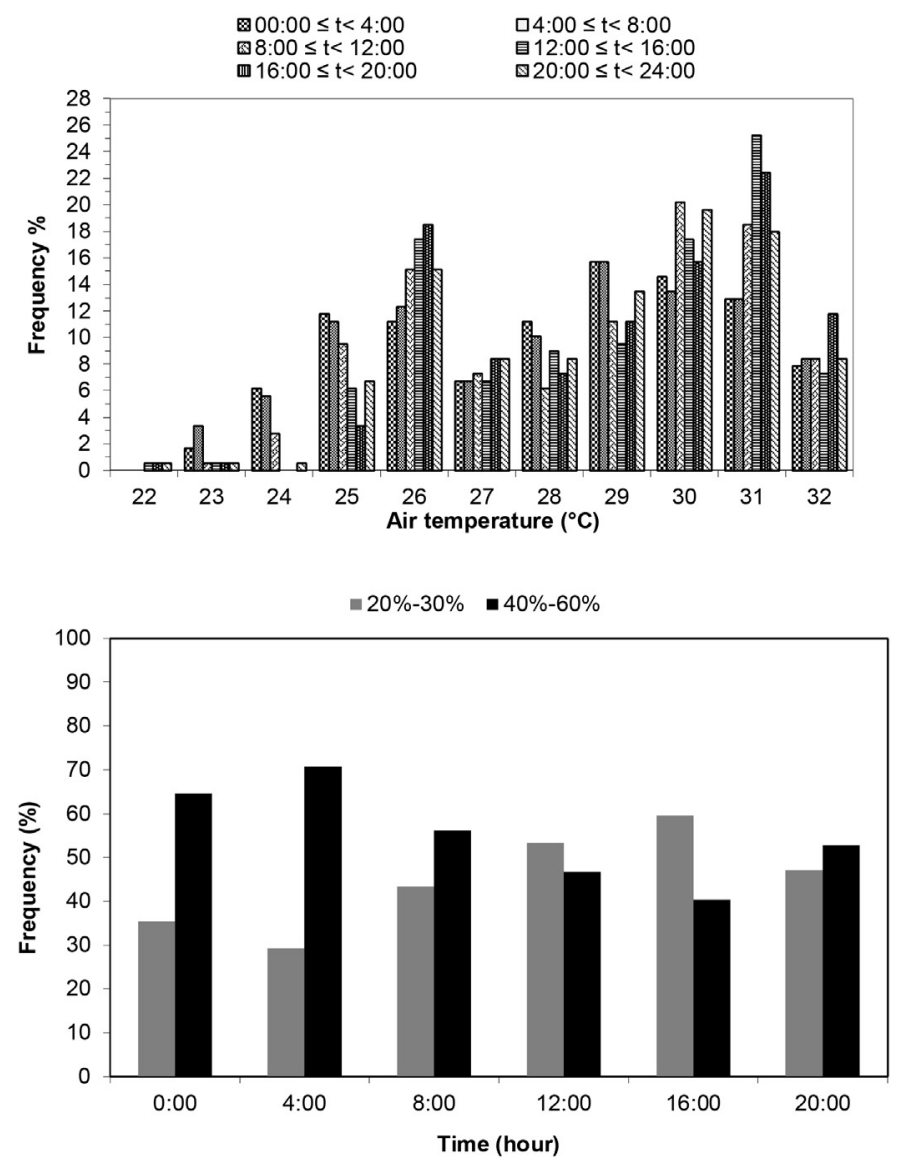

Fig. 8. Frequency distributions of the air temperature (upper panel) and the relative humidity (lower panel).
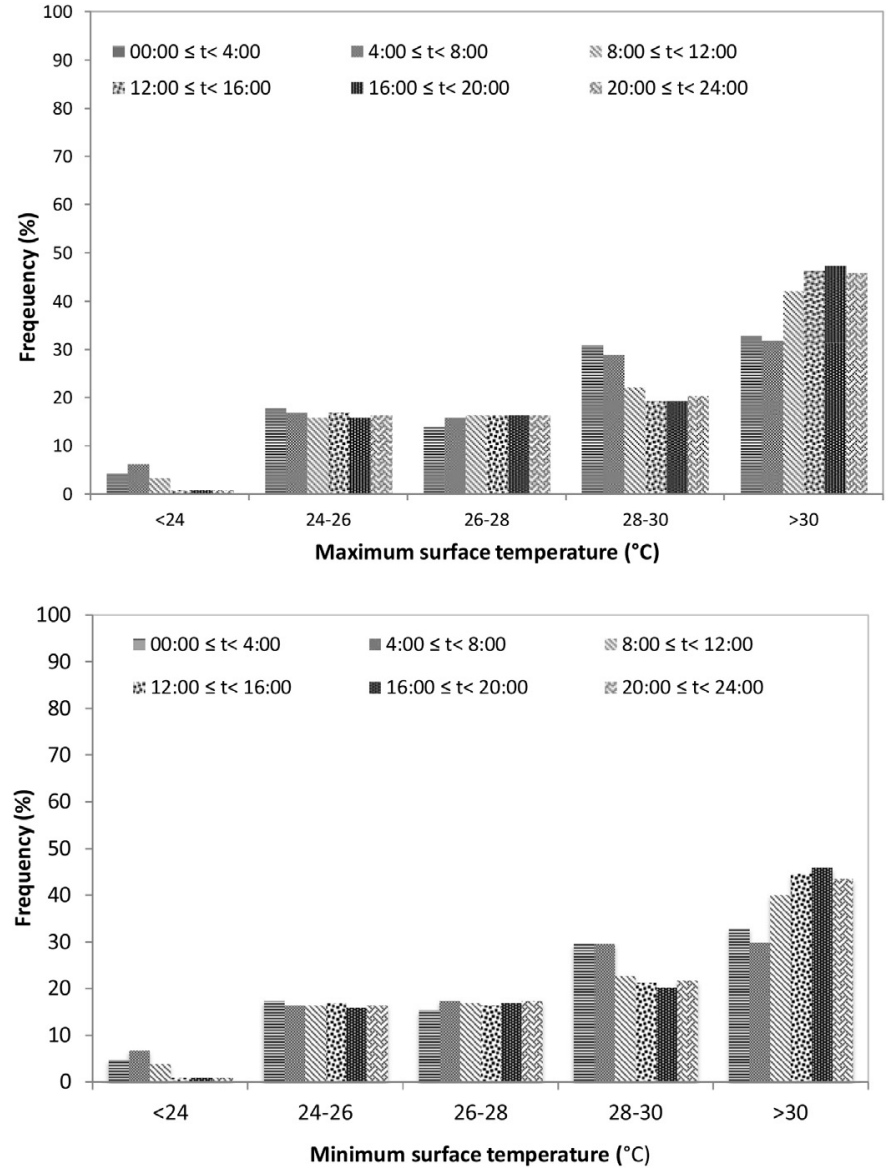

Fig. 9. Frequency distributions of the maximum surface temperature (upper panel) and the minimum surface temperature (lower panel).

Looking at the F\% of maximum and minimum surface temperature $\left(\mathrm{Tc}_{\max }\right.$ and $\mathrm{Tc}_{\min }$ respectively) at $4 \mathrm{~h}$ interval (Fig. 9 upper and lower panel respectively), a prevailing occurrence of $\mathrm{Tc}_{\max }$ for the time span 18:00-21:00 was observed.

The lighting system and the large number of visitors may have contributed to the overheating.

Regarding $\mathrm{Tc}_{\mathrm{min}}$ data, two patterns can be distinguished: the first between $24^{\circ} \mathrm{C}$ and $28^{\circ} \mathrm{C}$ (from April to May and on October) and the second above $28^{\circ} \mathrm{C}$ (from June to September), in accordance with air temperature frequency distribution.

Furthermore the difference between the air and the surface temperature, $\Delta(\mathrm{Ta}-\mathrm{Tc})$, was taken into account as indicators of heat fluxes. The frequency distribution of $\Delta(\mathrm{Ta}-\mathrm{Tc})$ at $4 \mathrm{~h}$ intervals showed the most critical situation with larger heat exchange: $\Delta(\mathrm{Ta}-\mathrm{Tc})>1{ }^{\circ} \mathrm{C}$ (that is $>+2$ std) and $\Delta(\mathrm{Ta}-\mathrm{Tc})<0.5^{\circ} \mathrm{C}$ (that is $<-1$ std).

The surface temperature resulted higher than the air temperature mainly during the night when the surface, which warms up during the day, cools down more slowly. Air temperature increases during daily hours $(8: 00-16: 00)$ to which the large number of visitors contributes. This phenomenon occurred in particular in July, with large difference in temperature between day and night.

The RH F\% calculated at $10 \%$ intervals of relative humidity showed $\mathrm{RH}=40 \%$ as the most frequent value (Fig. 8, lower panel). This value was found during the first $12 \mathrm{~h}$ of the day while during the afternoon the microclimate becomes dryer with $\mathrm{RH}<30 \%$.

Based on the Ta and RH data the dew point temperature (Td) was determined. The temporal behavior of air and surface temperature shows that the dew point was never reached (Fig. 10). This result confirms the dryness of the environment. 


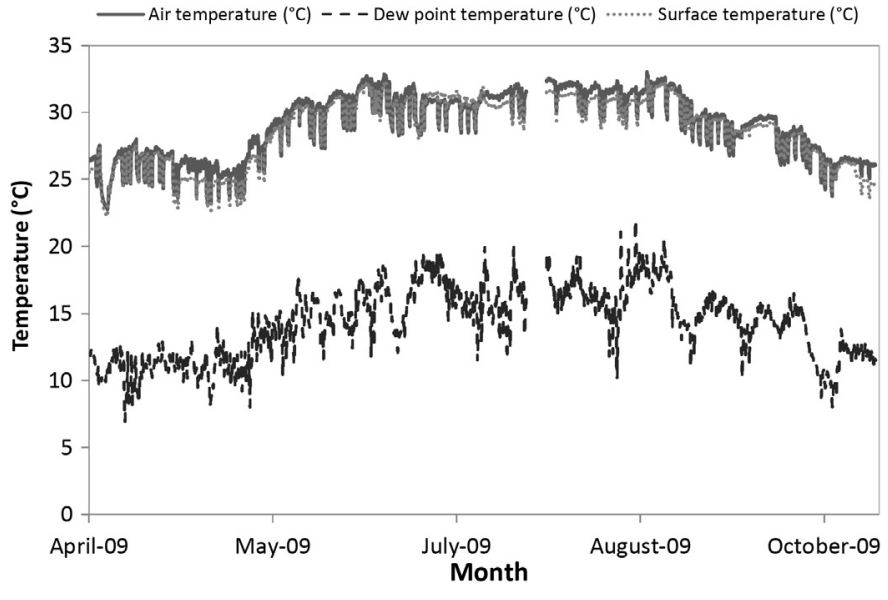

Fig. 10. The temporal behavior of air temperature, surface temperature and dew point temperature.

The relationship between panel surface temperature and dimensional variation of cracks was investigated using crackmeters and then calculating the Pearson's correlation coefficient. A large negative correlation ranging from -0.6 to -0.8 was found.

Over the period under study, the specific humidity was in the order of $8 \mathrm{~g} / \mathrm{kg}$. The variability during the day was often larger than $1.8(\mathrm{~g} / \mathrm{kg}) /$ day (i.e. $1 \mathrm{std})$, mainly in July and August.

Finally, the $\mathrm{CO}_{2}$ concentration (ppm) was considered as indicator of the number of visitors in the Room. The frequency distribution calculated at $4 \mathrm{~h}$ intervals, showed maximum values (from $500 \mathrm{ppm}$ to $1000 \mathrm{ppm}$ ) between 12:00 and 16:00, while the highest concentration was reached in October $\left(1000<\left[\mathrm{CO}_{2}\right]<2000 \mathrm{ppm}\right)$ during a temporary exhibition. $\mathrm{CO}_{2}$ concentration had never reached dangerous level for human health (5000 ppm).

\subsection{Lighting analysis}

On 8 March 2010 lighting measurements were performed on several areas of panel no. 3, between 12:00 and 15:00 local time. It was found that $73 \%$ of $E$ measured values resulted above the threshold of $150 \mathrm{~lx}$ [22] and $66 \%$ of $E$ values were in the range 150-300 lx. Since the lightning values, LO was estimated dividing the measured $E$ values into four classes (Table 1) and considering the length of time the lights are on during the day, and by summing up hourly values. In the Borghese Gallery lights are usually switched on from $7.00 \mathrm{am}$ until closing time $(7.00 \mathrm{pm})$. The Gallery is open 363 days per year. Under the above conditions LO was then estimated to be $1.1 \mathrm{Mlx}$ h per year when $E_{\max }$ is $258.60 \mathrm{~lx}$ and $0.6 \mathrm{Mlx} \mathrm{h}$ per year when $E_{\max } 139.27 \mathrm{~lx}$ were taken into account (Table 1). Consequently it appears that LO resulted above the threshold of $0.5 \mathrm{Mlx}$ h for gypsum [23]. By contrast UVA values resulted within the threshold of $75 \mu \mathrm{W} \mathrm{lm}^{-1}$ [22].

\section{Table 1}

The four classes of the intensity of lighting on the unit area, $E$ (expressed in lumen per square meters, i.e. lx) set by the norm UNI 10829 [20]. $E_{\mathrm{Max}}$ is the measured maximum lighting value and $F$ is percentage of the $E$ classes. The total annual dose of lighting (LO) was estimated for each class considering the length of time lights are turned on during the day and by summing up hourly values.

\begin{tabular}{lrll}
\hline$E(\mathrm{~lx})$ & $F(\%)$ & $E_{\mathrm{Max}} \pm \Delta E^{\mathrm{a}}$ & $\begin{array}{l}\text { LO (Mlx h } \\
\text { per year })\end{array}$ \\
\hline$E \leq 50$ & 0 & & \\
$50<E \leq 150$ & 27 & 139.27 & 0.6 \\
$150<E \leq 300$ & 66 & 258.6 & 1.1 \\
$E>300$ & 7 & & \\
\hline
\end{tabular}

a $\Delta E<0.5 \%$ of reading value.
However, the real problem for the stucco is not the visible light intensity [22] but the overheating for dissipation, especially due to the IR component $[6,18]$. In facts the $T_{\text {rad }}$ values, measured on some points of panel no. 3, showed higher temperatures (from $20^{\circ} \mathrm{C}$ to $22^{\circ} \mathrm{C}$ ) near the halogen sources.

\section{Conclusions}

The analyses of the material provided information on the "scagliola" technique used for the stucco panels on the vault of Galleria Borghese, Room VI: a mixture of gypsum, lime, an organic glue and sand which was ascertained by chemical and mineralogical analysis. The presence of a heavy molecular compound indicates that could be a protein.

The results of the analysis of the indoor climate, surface temperature and lighting measurements have allowed to formulate possible causes behind the degradation mechanisms: the synergy among the type of material, the daily and seasonal thermohygrometric cycles and the lighting system in use seem to be responsible for the cracks.

The porous and hygroscopic material structure favors the exchange of vapour and heat between the stucco and air. It was found that both environment conditions of Room VI and those around the panel are warm (during the summer, at midday, the maximum temperature is $32^{\circ} \mathrm{C}$ nearby the panel).

The most serious problem seems to derive from the incandescence lamps positioned on the ledge in front of the panels. The measurements showed that the decay occurs in those parts of the panel overheated by incandescence lamps. The damage can be related to the inadequate choice of incandescence lamps and to their location right in front of the panels. The high temperature of the vault is another consequence of this lighting system.

The relationship between panel surface temperature and the dimensional variation of the cracks indicates that when the temperature increases, the compression exerted by the expanding material wedged between the wall boundaries, forces the cracks to decrease in width as a result of internal stress. In the case of stucco, dimensional changes do not follow the asymmetric behavior typical of wood. Nonetheless, if the panel has resisted under reasonably acceptable conditions for over four centuries and now rapidly deteriorates, we should consider that the recent microclimate changes have been unfavorable. For this reason we should take into account that the excess overheating cycles due to swarm of visitors and in particular the incandescence lighting, constitute a serious problem.

The following measures are suggested:

- To replace the halogen incandescent lights with cold light sources, i.e. light-emitting diodes (LED) with low thermal infrared emissions or, alternatively, fluorescent compact lamps. We expect that changes in the lighting system will be beneficial to reduce the heat in air layering under the ceiling. In the case this measure is not sufficient, the suggestion is to optimize the HVAC system.

- To prevent opening windows randomly during the day.

- To check periodically the results of the above measures to identify and achieve optimal conditions for conservation and to prevent or reduce the need for future restorations.

\section{Acknowledgements}

The authors are grateful to Prof. M. Colapietro (Sapienza University of Rome), Dr M.L. Santarelli (CISTeC) and Dr D. Capitani (Magnetic Resonance Laboratory "Annalaura Segre”, CNR, Rome) for their contribution in the analysis of material. Thanks are due to Dr M.T. Lepone for her support in conducting the lighting 
measurements and to the Techno-el s.r.l. which has installed the measurements microclimate system and developed the GRILLO MMTS data logger with remote transmission of data.

\section{References}

[1] P. Della Pergola, B. La Galleria, Itinerari dei musei, gallerie e monumenti d'Italia. Ministero della pubblica istruzione. Direzione generale delle antichità e delle belle arti, Arnauld, Florence, 1972.

[2] Touring Club Italiano, Dossier Musei, 2009.

[3] A. Coliva, La stanza del Gladiatore, Milano, Skira, 2004

[4] D. Colli, La scagliola carpigiana e l'illusione barocca, Modena Artioli, Modena, 1990.

[5] A. Massinelli, Scagliola l'arte della pietra di luna, Roma, Editalia, 1997.

[6] D. Camuffo, Microclimate for cultural heritage, Elsevier, Amsterdam, 1998.

[7] D. Camuffo, P. Brimblecombe, R. Van Grieken, H. Busse, G. Sturaro, A. Valentino, et al., Environmental monitoring in four European museums, Atmospheric Environment 35 (Suppl. 1) (2001) 127-140.

[8] M. Strada, A. Carbonari, F. Peron, L. Porciani, P. Romagnoni, The microclimate analysis of tezone ' 105 ' of the Venetian Arsenale, Journal of Cultural Heritage 3 (2002) 89-92.

[9] S.P. Corgnati, V. Fabi, M. Filippi, A methodology for microclimatic quality evaluation in museums: application to a temporary exhibit, Building and Environment 44 (2009) 1253-1260.

[10] G. Pavlogeorgatos, Environmental parameters in museums, Building and Environment 38 (12) (2003) 1457-1462.

[11] A.W.M van Schijndel, H.L. Schellen, J.L. Wijffelaars, K. van Zundert, Application of an integrated indoor climate, HVAC and showcase model for the indoo climate performance of a museum, Energy and Buildings 40 (2008) 647-653.

[12] A.M. Papadopoulos, A.M. Avgelis, Santamouris energy study of a medieval tower, restored as a museum, Energy and Buildings 35 (2003) 951-961.
[13] B. Bøhm, M. Ryhl-Svendsen, Analysis of the thermal conditions in an unheated museum store in a temperate climate. On the thermal interaction of earth and store, Energy and Buildings 43 (2011) 3337-3342.

[14] F. Becherini, A. Bernardi, E. Frassoldati, Microclimate inside a semi-confined environment: valuation of suitability for the conservation of heritage materials, Journal of Cultural Heritage 11 (4) (2010) 471-476.

[15] EN, Conservation of cultural property - Specifications for temperature and relative humidity to limit climate-induced mechanical damage in organic hygroscopic materials. European Committee for Standardization (CEN), 2010, EN 15757.

[16] EN, Conservation of cultural property - Procedures and instruments for measuring temperatures of the air and the surfaces of objects. European Committee for Standardization (CEN), 2010, EN 15758.

[17] EN, Conservation of cultural property -- Procedures and instruments for measuring humidity in the air and moisture exchanges between air and cultural property. European Committee for Standardization (CEN), 2012, EN 16242.

[18] EN, Guidelines and procedures for choosing appropriate lighting for indoor exhibitions. European Committee for Standardization (CEN), 2012, EN 16163.

[19] UNI, Cultural heritage-general principles for the choice and the control of the microclimate to preserve cultural heritage in indoor environments, Italian Standard, 2002, UNI 10969.

[20] J. Chapman, R. Smith-McNally, Storing handling plaster objects, Conserve O Gram 8 (2) (1997) 1-4

[21] D. Camuffo, Thermodynamic exchanges between the external boundary layer and the indoor microclimate at the basilica of Santa Maria Maggiore, Rome, Boundary-Layer Meteorology 92 (2) (1999) 243-262.

[22] PAS, Specifications for managing environmental conditions for cultural collections, British Standard Institution (BSI), London, PAS, 2012, 198

[23] UNI, Works of art of historical importance-ambient conditions for the conservation-measurements and analysis, Italian Standard, 1999, UN 10829 